\title{
A new measure of competition in Indian loan markets
}

\author{
a Jugnu Ansari \\ ${ }^{a}$ Assistant Adviser, CAFRAL, C-7, RBI, Bandra-Kurla Complex, Bandra(East), Mumbai-400051, India
}

\begin{abstract}
This study examines bank competition in the loan markets in India using a new competitiveness index, the Augmented Relative Profit Difference (ARPD). The ARPD quantifies the impact of marginal costs on performance, measured in terms of market shares. The theoretical foundation of the ARPD is robust when compared to other conventional measures. Applying this unbiased competition indicator to loan markets shows that financial reform has contributed to significant improvements in competition. Public sector banks and private sector banks are more competitive than foreign banks too. In addition, we find that the Indian loan markets are monopolistic in nature.
\end{abstract}

Keywords: Loan market; Competition; Marginal Cost; Banking Industry

(C) 2013 Published by SSBFNET

\section{Introduction}

It is well known that the financial system in India is predominantly a bank-based system. Banks function as depositories for household savings and provide credit services, apart from financing the government through investment in Treasury securities. Until the early 1990s, public sector commercial banks performed all of these functions in a highly-regulated environment guided by domestic banking for economic development and a fiscal policy dominated by macro policy objectives. In such an environment, banks could not market or promote their businesses with regard to asset quality and profitability. In the wake of the balance of payment crisis, India implemented a series of reform measures designed to alleviate structural impediments to economic growth through a competitive and open economic model. At this juncture, it was determined that meaningful economic reform could not take place without an overhaul of the financial system. Thus, banking sector reform was pursued based on the recommendations of a high-level committee. The reform measures included promoting a diversified, efficient, and competitive financial system with the ultimate goal of improving the allocative efficiency of resources through operational flexibility, improved financial viability, and institutional strengthening. The banking sector reform encompassed five dimensions. First, the level of competition was gradually increased within the banking system by allowing greater participation of domestic private and foreign banks while allowing banks greater freedom in pricing and allocating credit. Second, measures were taken to develop various segments of the financial markets, such as money, bond, credit, foreign exchange, and equity. The concept was to allow banks and financial institutions to offer

\footnotetext{
${ }^{\text {a }}$ Corresponding author.Jugnu Ansari, Tel:+912226571014
} 
investors opportunities for diversification, portfolio optimization, and effective management of liquidity and other risks. Third, in order to ensure stability of the financial system, banks were subjected to international best practices in prudential regulation and supervision tailored to Indian requirements. The supervisory system of the Board for Financial Supervision was revamped with the goal to create an efficient banking system. Fourth, measures were taken to improve the institutional arrangements of banks including their legal frameworks and technology platforms for effective, cost efficient, and sound payment and settlement. Finally, in order to be consistent with the new institutional architecture for the financial system in general and the banking sector in particular, the monetary policy shifted from direct instruments of monetary management such as cash reserves and statutory liquidity requirements to an increasing reliance on indirect instruments such as short-term interest rates including repo and reverse repo rates. Thus, there was a shift from the traditional mode of money transfer to an interest rate channel of monetary transmission. Policy planners envisioned that in a competitive and integrated financial market environment, banks will be guided by market conditions, balance sheet pressures, and regulatory and prudential requirements. In a competitive marketplace, readily available credit can have a significant impact on the economy. A banking system that exhibits some degree of market power, however, may improve credit availability to certain banks. It may also provide incentives for banks to screen loans, which aids efficient allocation of resources. Market power in a banking system may contribute to stability by providing incentives that mitigate risk-taking behavior, and by providing incentives to screen and monitor loans, which can improve the quality of banks' portfolios. Policies such as capital requirements, disclosure rules, and riskbased deposit insurance, however, are incentives for banks to behave prudently even in a competitive market. A new approach to measure competition was introduced and applied by Boone $(2000,2004,2008)$. The so-called Boone indicator (Relative Profit Difference or RPD) measures the impact of efficiency on performance in terms of profits or market shares. The idea behind the RPD is that competition enhances the performance of efficient banks and impairs the performance of inefficient banks. This approach is related to the well-known efficiency hypothesis, which also explains bank performance by differences in efficiency (Goldberg and Rai, 1996; Smirlock, 1985). This method allows measurement of competition for the entire banking sector, as well as for separate product markets, such as the loan market, and for single types of banks, such as commercial and cooperative banks. In this study, we use the augmented RPD (ARPD) measure to evaluate competition in the Indian banking sector. Generally, policymakers support a banking system that promotes economic efficiency and stability and they want to evaluate whether a policy change had the desired effect. To illustrate, a regulatory body may want to monitor an industry so that it can intervene when competition slackens; they implement a policy change with the goal of intensifying competition in a faltering industry. Competition in the financial sector is vital for a number of reasons: (1) for the efficient production of financial services, (2) the quality of financial products, and (3) the degree of innovation in the sector. The degree of competition in a financial sector impacts the availability of financial services and external financing, which affects economic growth, although not all relationships are clear. The theory of industrial organization is based on the concept that the competitiveness of an industry cannot be measured by market structure indicators alone, such as the number of institutions, the Herfindahl index or other concentration indexes (Baumol, Panzar, and Willig, 1982). The threat of market entry can be a more important determinant of the behavior of market participants (Besanko and Thakor, 1992). Theory also suggests that performance measures, such as the size of a bank's margins or profitability, do not necessarily indicate the competitiveness of a banking system. Performance measures are influenced by a number of factors, such as a country's macro performance and stability, the form and degree of taxation, the quality of the country's information and judicial systems, and bank-specific factors, such as scale of operations and risk preferences. As such, these measures can be poor indicators of the degree of competition. 
The rest of the paper is presented in five sections. In Section 2, we review the literature. In Section 3, we discuss the theoretical perspectives, methodology, and data, followed by a discussion of stylized facts in Section 4. In Section 5, we present the empirical analyses. We present concluding remarks is Section 6.

\section{Literature Review}

The evidence of measuring the level of competition in the Indian banking system is scarce. There have been a few studies that have investigated the degree of competition in Indian financial industries. Prasad and Ghosh (2005) estimated the Panzar and Rosse (1987) H-statistic of Indian banks for the 1996 to 2004 period. They found that the Indian banking sector was in monopolistic competition equilibrium. Murthy and Deb (2008) used Bodenhorn's Measure of Mobility to measure the competition in Indian private sector banks for the 1992-2002 periods. They found that the market structure of the private banking sector in India is monopolistic. Testing for the degree of effective competition requires a structural contestability approach, along the lines pursued in much of the industrial organization literature. As in other sectors, the degree of competition in the banking system should be measured with respect to the actual behavior of the (marginal) bank. The actual behavior should be related not only to banking market structure but also to entry barriers, including barriers on foreign ownership, as well as the severity of activity restrictions since those can limit intra-industry competition. Furthermore, the degree of competition from other forms of financial intermediation (capital markets, nonbank financial institutions, insurance companies) will play a role in determining banking system competitiveness. As a first-order effect, one would expect increased competition in the financial sector to lead to lower costs and enhanced efficiency, even allowing for the fact that financial products are heterogeneous. Recent research has illustrated, however, that the relationships between competition and banking system performance, access to financing, stability, and growth are more complex. Market power in banking, for example, may be beneficial for access to financing (Petersen and Rajan, 1995). The view that competition is unambiguously good in banking is more naïve than in other industries, and vigorous rivalry may not necessarily be beneficial for financial sector performance. This literature has also shown that technology that lowers production or distribution costs for financial services providers does not necessarily lead to more or better access to finance. A number of people have investigated banking system competition. Berger and Hannan (1989) investigate the commonly observed relationship between market concentration and profitability using data for U.S. banks from 1983 to 1985. They try to separate the effects of noncompetitive price behavior from that of greater efficiency for firms with larger market share and find that noncompetitive price behavior could explain the relationship. While many of the studies are not formal structureperformance-conduct tests, their results have been interpreted as being indicative of the degree of competition and/or its causes and consequences in the financial sector (Berger, 1995). Recent studies have investigated how regulations and specific structural or other factors impact bank performance. Barth, Caprio, and Levine (2004) document, among others, that tighter entry requirements are negatively linked with bank efficiency, leading to higher interest rate margins and overhead expenditures, while restricting foreign bank participation tends to increase bank fragility. These results are consistent with the view that tighter entry restrictions tend to limit competition and emphasize that it is not the actual level of foreign presence or bank concentration but the contestability of a market that determines bank efficiency and stability. A number of people have applied either the Bresnahan (1982) or the Panzar and Rosse (1987) methodology to the issue of financial sector competition, although mostly to the banking system specifically. Cetorelli (2004) provides more detail on these formal tests and reviews the results of empirical banking studies. One of the first applications of the Bresnahan test is that of Shaffer (1989). For a sample of U.S. banks, his findings strongly reject collusive conduct but are consistent with perfect competition. Using the same model, Shaffer (1993) finds that the 
Canadian banking system was competitive over the 1965-1989 period despite being relatively concentrated. Gruben and McComb (2003) find that the Mexican banking system before 1995 was more competitive, that is, marginal prices were set below marginal costs. Shaffer (2001) uses the Bresnahan (1982) model and examines 15 countries for the 1979-1991 period in North America, Europe, and Asia. He finds significant market power in five markets and excess capacity in one market. Estimates were consistent with either contestability or Cournot type oligopoly in most of these countries, while five countries were significantly more competitive than Cournot behavior would imply. Shaffer (1982) applied the Panzar and Rosse model to a sample of New York banks using data for 1979 and found monopolistic competition. Nathan and Neave (1989) studied Canadian banks using the Panzar and Rosse methodology and found results consistent with the results of Shaffer (1989) using the Bresnahan methodology (i.e., a rejection of monopoly power). Several studies have applied the Panzar and Rosse methodology to European banking systems. Generally, the studies reject both perfect collusion and perfect competition and largely find evidence of monopolistic competition (Bikker and Haaf, 2001). Some studies find differences between types of banks. For example, De Bandt and Davis (2000) find monopoly behavior for small banks in France and Germany while they find monopolistic competition for small banks in Italy and for the large banks in all three countries in their sample. This suggests that in these countries small banks have more market power perhaps as they cater more to local markets. The price cost margin (PCM) is widely used as a measure of competition. However, the theoretical foundations of PCM as a competitive measure are not robust. Theoretical papers like Amir (2002), Bulow and Klemperer (1999), Rosentahl (1980), and Stiglitz (1989) present models where more intense competition leads to higher PCMs instead of lower margins. Boone (2008) assumes that more efficient firms (i.e., firms with lower marginal costs) will have a greater share of the market and higher profits, and that this effect will be stronger in more competitive markets. In order to support this intuitive market characteristic, Boone (2000, 2001, and 2008; Boone et al., 2004) develops a broad set of theoretical models and finds them to be more robust than any other methods (e.g., PCM, HHI, H-statistic). Both competition and market power, however, can have positive implications for efficiency and prudent regulation. It may be advisable to facilitate competitive behavior (contestability), thereby minimizing the potential costs of market power while realizing whatever benefits may be associated with any residual market power. In contrast, structural variables do not have a significant impact on market competition, as measured by the $\mathrm{H}$-statistic. Contestability appears to be more important than market structure in explaining the strength of competition in the banking sector. In general, four approaches have been used to measure competition in the banking sector: PCM, HHI, H-statistic, and Augmented Relative Profit Difference (ARPD). The ARPD method is used in this study to measure competition in the Indian banking sector.

\subsection{Structural measures of competition}

Familiar measures of market structure, such as concentration ratios, the number of banks, and the HerfindahlHirschman Index (HHI), are still widely used in empirical work. These measures originated in the structure-conductperformance (SCP) paradigm linking the structure of a market to influences on bank behaviour and thus sector performance. One prediction of the SCP approach is that higher concentration would encourage collusion and reduce efficiency. However, the SCP paradigm has well-known weaknesses. Structure may not be exogenous; it might be due to bank behaviour. A more concentrated market structure could be the result of better, more efficient performance, contrary to the predictions of the SCP paradigm. There is no consensus on the most appropriate variable for measuring market structure in banking; performance is typically measured with variables, such as net interest margins or 
profitability, which can be influenced by factors other than the degree of competition, such as a country's macroeconomic situation or the level of taxation.

\subsection{Measures of market contestability}

The PCM approach can be used to assess competitive conditions in terms of contestability. It is widely used as a measure of competition. It is believed that there are two reasons why PCM is still such a popular empirical measure of competition. First, as long as there is no evidence that the theoretical counterexamples are important empirically, one would expect that PCM remains a popular competition measure. The second reason for the popularity of PCM is that the data needed to get a reasonable estimate of PCM are available in most datasets. A concentrated banking sector can remain competitive if it is contestable, that is if entry and exit into the system is easy and if bank regulations and supervision promote a level playing field. Variables like regulatory indicators of entry requirements, the presence of foreign ownership, formal and informal entry barriers, and activity restrictions measure the threat of entry in the sector and thus its contestability through the degree of entry and exit. Indeed, the standard approach used in the literature to retrieve the PCM specifies a demand function and the derivation of its first-order equilibrium condition, in which it is shown that (e.g. ,in the Cournot case) for a given bank ' $i$ ' the first-order condition (FOC) amounts to $L i=\alpha_{i} / \varepsilon$, where $\alpha_{i}$ is the market share of the bank, $\varepsilon$ is the elasticity of demand, and $L i$ is the PCM, or Lerner Index, calculated as ( $P$ $M C) / P$, i.e., how far a bank's price is from its marginal cost. Two different empirical versions of the Lerner Index approach are available in the literature, and both can be used at the bank level of analysis, since they only need the availability of balance sheet data. The basic one is a simple ratio between the profits and assets of a single bank, as in the case of Aghion et al. (2005) and Nickell (1996). However, theoretically, PCM is not a robust measure of competition; it has an aggregation problem. When aggregating from a bank-level PCM to an industry-level PCM using a weighted average method, where the weight of a bank equals its market share in the industry, there are possibilities for a wrong inference of the competitive measure using the PCM approach. An increase in competition reallocates market share from inefficient banks to efficient banks. Since efficient banks have a higher PCM than inefficient banks, the increase in competition raises the weight in the industry average PCM of banks with a high PCM, which can raise the industry average PCM (Wolfram, 1999; Boone, 2004), although this may not be an accurate indication of competition. Amir (2003) shows that, under certain conditions, an increase in competition through an increase in the number of banks in a market can result in an increasing average PCM. Stiglitz (1989) shows that under certain circumstances, profits per unit sales can rise during a recession. Thus, even though competition among banks increases during recessions, industry PCM also increases. Another potential source of error can be the reallocation effect. As a result of fiercer competition, the market share of the more efficient banks increases while it decreases for less efficient banks. Thus, the weighted average PCM can increase if the increase in the market share of the more efficient banks over-compensates the decrease of the respective individual PCMs. Therefore, the Lerner Index (i.e., PCM) is, at least theoretically, potentially misleading.

\subsection{Direct measures of competition}

The so-called H-statistic approach measures the intensity of competition directly, in the way prices or outputs respond to costs. Many recent studies of banking use the H-statistic based on the Panzar and Rosse (1987) methodology, which proxies the reaction of output to input prices. The $\mathrm{H}$-statistic is calculated by summing the estimated elasticities of 
revenue to factor prices; a value of one indicates perfect competition, a value of zero (or less) indicates monopoly, and intermediate values indicate the degree of monopolistic competition. The index ranges from a high of 1 to a low of 0 , with higher numbers implying greater market power. The theoretical foundation for direct measures is stronger than for structural measures, but direct measures have drawbacks too. For example, the H-statistic imposes restrictive assumptions on a bank's cost functions. This measure neglects differences among banks like size, product or geographic differentiation. Still, this approach is increasingly used in empirical research because it measures bank behaviour and thus competition directly.

\subsection{Augmented Relative Profit Difference}

Boone (2008) proposed a new competition measure, the Relative Profit Difference (RPD). Despite its theoretical robustness, few studies have applied the RPD to real-world data. The only paper published in a refereed technical journal, to our knowledge, is Bikker and Leuvensteijn (2008). Using data for the Dutch life insurance market, they calculate RPD using different approximations of the variable costs. The RPD measure overcomes the problems of heterogeneity, aggregation, and attrition that could have arisen in the previous sections. Moreover, this variable can be constructed using the same bank-level data used to calculate the PCM, without any additional data requirements. It could be the case that a more efficient bank would report lower costs (then having a higher bank-level PCM), whereas less efficient banks would report higher costs (therefore lower bank-level PCM). Given a competitive shock in the sector due to more aggressive behaviour by the incumbents (e.g., a lower elasticity of substitution among products), a less efficient bank would exit and their market share would be distributed among the other banks, hence eventually increasing the aggregate PCM. This is a case where a positive competitive shock determines a higher sector-level PCM, implying that, under particular circumstances, the PCM measure is not monotonic in competition. The RPD measure instead increases (decreases) not only for the enhanced (lower) competition that arises from lower entry barriers, but also for competition that reallocates output to another bank, thus ensuring the respect of monotonicity with respect to the direction of the competitive shock.

\section{Theoretical perspectives}

The competitiveness index (Augmented Relative Profit Difference) was devised by Boone (2008) and is robust as compared to traditional measures of competition. Several studies concluded that countries with fewer entry and activity restrictions tend to have stronger competition. In contrast, structural variables do not have a significant impact on competition, as measured by the H-statistic. Contestability appears to be more important than market structure in explaining the strength of competition in the banking sector. Another strand of studies, however, finds that bank size matters for market power, and in the way predicted by the Structure-Conduct-Performance (SCP) paradigm. Competition is found to decrease significantly with bank size. This may be because large banks are in a better position to collude with other banks, or because large banks are more likely to operate in less competitive markets.

Boone (2008) proposes a new competition measure, termed Relative Profit Difference (RPD), which is defined as follows. Let $\pi(\mathrm{n})$ denote the variable profit level of a bank with efficiency level $n \in R+$ where higher $n$ denotes higher efficiency. Consider three banks with different efficiency levels, $n^{\prime \prime}>n^{\prime}>n$, and calculate the RPD as follows:

$$
R P D\left(n^{\prime}, N, I, \theta\right)=\frac{\pi\left(n^{\prime \prime}, N, I, \theta\right)-\pi(n, N, I, \theta)}{\pi\left(n^{\prime}, N, I, \theta\right)-\pi(n, N, I, \theta)} .
$$


The more intense the competition (e.g., lower entry cost or more aggressive interaction among banks), the higher the RPD. More precisely, a rise in competition reallocates output from less efficient banks to other banks. Since this output reallocation effect is a general feature of more intense competition, which is true for the RPD, it follows that RPD is a robust measure of competition from a theoretical point of view.When RPD is used as a measure of competition, three assumptions are always made, as postulated by Boone (2008): (1) Efficiency is one dimensional (i.e., banks under consideration act in a market with relatively homogeneous goods). If efficiency is, say, two dimensional, an increase in competition forces a bank to focus on the activity in which it is most productive. This may raise the bank-level price cost margin. If a bank's efficiency level is not observed, an increase in efficiency leads to a higher price-cost margin, which is then (incorrectly), interpreted as reduced competition. (2) A bank's efficiency level can be observed (i.e., we assume symmetry). Hence, banks act on a level playing field that ensures that changes in competition affect banks directly and not indirectly through changes in the playing field. It also implies that bank $i$ 's profits are the same as bank $j$ 's profits would be if bank $j$ was in bank $i$ 's situation. Thus, within the theoretical framework of the indicator, this implies an equal profit level for two equally-efficient companies. (3) Banks compete on a level playing field (i.e., we are able to rank banks with respect to their efficiency $(n)$ ). If banks compete on an uneven playing field, changes in competition can affect the status of the playing field, making it hard to interpret both RPD and PCM. Given a competitive shock in the banking sector due to more aggressive behaviour by other banks (e.g., a lower elasticity of substitution among products) with consequent lower prices, less efficient banks would exit and their market share distributed among other banks, eventually increasing the aggregate PCM. A positive competitive shock determines a higher sector-level PCM, implying that, under certain circumstances, the PCM measure is not monotonic. The RPD measure instead increases (decreases) not only for the enhanced (lower) competition that arises due to lower entry barriers, but also reallocated output to other banks, thus ensuring monotonicity with respect to the direction of the competitive shock.

We introduce a general model with ' $i$ ' banks that can enter and compete in a market. Banks are ranked such that a lower $i$ implies higher efficiency: $n 1 \geq n 2 \geq \ldots \geq n i$. Each bank $i$ chooses a vector of strategic variables, $a_{i} \in R_{k}$. This choice leads to output vector $q\left(a_{i} ; a_{-} ; \theta\right) \in R^{L}{ }_{+}$for bank $i$, where $\theta$ is a parameter that affects the aggressiveness of bank conduct in the market. Further, the choices of the strategic variables also lead to a vector of prices $p\left(a_{i} ; a_{\_} ; \theta\right) \in$ $R^{L}{ }_{+}$for bank $i$ 's products. Finally, we specify the costs of production for bank $i$ as $C\left[q\left(a i ; a_{i} ; \theta\right), n i\right]$. We say that $n_{i} \in$ $R_{+}$measures a bank's efficiency level.

The equilibrium variable profits are defined as follows:

$$
\pi(n i, N, I, \theta)=p(n i, N, I, \theta)^{T} q(n i, N, I, \theta)-C[q(n i, N, I, \theta), n i]
$$

The efficiency index $N$ needs to be one dimensional to ensure transitivity. Given that the production costs are captured by $C(q, n)$ as output quantity, the relationship between efficiency and cost is assumed to be:

$$
\frac{\partial C(q, n)}{\partial q l}>0
$$




$$
\begin{aligned}
& \frac{\partial C(q, n)}{\partial n} \leq 0 \\
& \frac{\partial\left(\frac{\partial C(q, n)}{\partial q l}\right)}{\partial n} \leq 0
\end{aligned}
$$

forl $\in\{1,2, \ldots, \mathrm{L}\}$.

The proposition of the first two quotients on the left-hand side is clear-cut. The first states that banks have positive marginal costs. The second quotient states that costs are lower the more efficient banks are. Finally, the quotient at the right-hand side states that marginal costs are lower for more efficient banks. Given these assumptions, banks play a two-stage game. In the first stage, they decide whether or not to enter a market. This is determined by the entry costs and the expected profit. Banks only enter if they are able to recoup entry costs. In the second stage, the remaining banks simultaneously choose their actions to maximize profits. This gives a sub-game equilibrium for each competitive state.

Boone (2008) uses two parameters to model changes in competition. One is the conduct parameter $\theta$, which mirrors the aggressiveness of banks. The second is the change in entry costs, $\varepsilon$. Then, the output reallocation effect works in the following way:

$$
\begin{gathered}
\frac{d \ln q(n)}{d \theta} \\
\text { and } \\
\frac{d \ln q(n)}{d(\varepsilon)}
\end{gathered}
$$

are increasing in $n$.

Given these conditions, while an increase in competition can decrease the output of banks, this decrease will be smaller for more efficient banks. As a result, the market share for the more efficient banks increases while that for the less efficient banks shrinks. Hence, competition rewards efficient banks. Given these settings, RPD is calculated as a quotient of profit-level differences:

$$
R P D(n, N, I, \theta)=\frac{\pi\left(n^{\prime \prime}, N, I, \theta\right)-\pi(n, N, I, \theta)}{\pi\left(n^{\prime}, N, I, \theta\right)-\pi(n, N, I, \theta)}
$$

Increasing competition raises this measure for any three banks, with $n^{\prime \prime}>n^{\prime}>n$. As Boone (2008) proves, his measure of competition is robust to distortions in response to the reallocation effect. However, if there are more than three banks, comparing RPDs over time for each bank is impractical. One convenient way, proposed by Boone (2008), is to graph the RPDs. Using a bank's normalized efficiency for the $\mathrm{x}$-coordinates gives a function that is always bounded at one on both axes. An increase in competition leads to lower bank-specific RPDs. To measure a change in 
competition, one calculates and compares the area under both curves. Since we have normalized values, the area is bounded between zero and one, with zero implying perfect competition and one the complete absence of competition. The area in our example shrinks and thus correctly indicates fiercer competition.

The bank-level measure of RPD is constructed as follows:

$$
R P D_{i t}=\frac{\pi_{t}(i)-\pi_{t}\left(i_{L}\right)}{\pi_{t}\left(i_{U}\right)-\pi_{t}\left(i_{L}\right)}
$$

where $\pi_{t}$ is profit at time $t, i$ is the bank whose RPD is measured, and $\left[i_{L}, i_{U}\right]$ is the set of banks in an industry and ranked by cost-efficiency, from the less efficient, $i_{L}$, to the more efficient, $i_{U}$. The inverse of normalized efficiency is:

$$
R C E_{i t}=\frac{C_{t}\left(i_{U}\right)-C_{t}\left(i_{L}\right)}{C_{t}(i)-C_{t}\left(i_{L}\right)} .
$$

One advantage of the RPD measure is that one does not need to observe all banks in an industry to calculate it properly. Since the result holds for any subset of banks sampled, increasing competition would in any case pull down the entire curve. Another interesting feature of the RPD measure is that it is also strongly correlated with the within effect of the PCM decomposition previously analyzed (Boone et al., 2007). The latter allows us to further assess the robustness of the within effect as a selection indicator.

\section{Data and methodology}

In this study, we use annual bank balance sheet and income statement data for the 1996-2011 period retrieved from the 'Statistical Table Relating to Banks in India' published by RBI and Prowess Database of CMIE. Our data set covers all the major banks in the public, private, and foreign sectors.

\subsection{A non-parametric measure of competition:RPD}

Using a bank-level panel data set, we estimated RPD measure to evaluate competition in the Indian loan markets. Our analysis reveals that the non-parametric RPD approach fails to correctly indicate competition. The non-parametric RPD is defined as:

$$
R P D_{i t}=\frac{\pi_{t}(i)-\pi_{t}\left(i_{L}\right)}{\pi_{t}\left(i_{U}\right)-\pi_{t}\left(i_{L}\right)}
$$

where $\pi_{t}$ is profit at time $t, i$ is the bank whose RPD is measured, and $\left[i_{L}, i_{U}\right]$ is the set of banks belonging to a given industry and ranked by cost-efficiency, from the less efficient, $i_{L}$, to the more efficient, $i_{U}$. One convenient way, proposed by Boone (2008), is to graph the RPDs using the bank's normalized efficiency and normalized profits. The increase in competition leads to lower bank-specific RPDs. To measure competitive change, calculate and compare the area under the curves. Since we have normalized the values, the area is bounded between zero and one, with zero implying perfect competition and one the complete absence of competition. In this case, the more competitive a sector, 
the more the curved line would be pulled to the bottom right. From the graph, the levels of competition within a sector can be computed as the area below the RPD curve. The smaller the area below the curve, the higher is the level of competition.

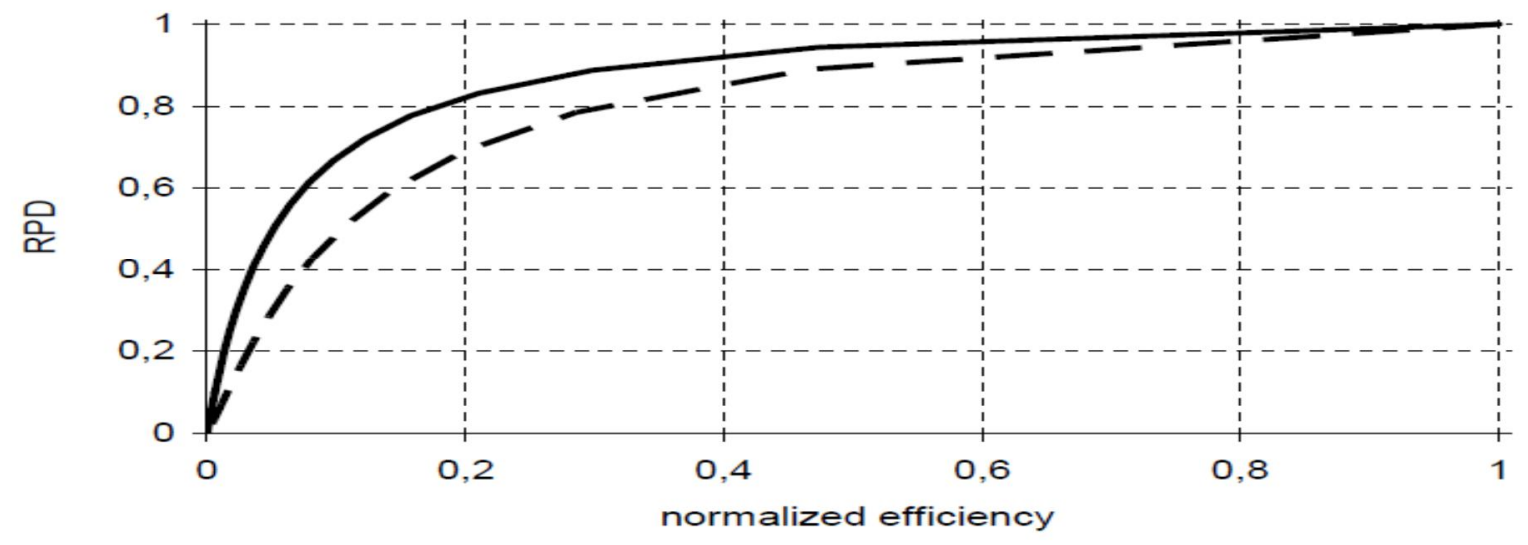

Figure 1: Efficiency and RPD

Figure 1 shows that as the slope of the curve decreases, the area under the curve decreases, indicating a corresponding increase in competition. Using the same intuition, an alternative parametric approach of ARPD is proposed below.

\subsection{A parametric measure of competition: $A R P D$}

Theoretically, loan market competition increases in two ways. First, competition increases when the services of various banks become closer substitutes and entry costs decline. Boone et al. (2004) suggest that the market shares of more efficient banks increase both under stronger substitution and lower entry costs. So the following relationship between market share and marginal cost is (Leuvensteijn, 2007):

$$
\ln \left(s_{i}\right)=\alpha+\beta \ln \left(m c_{i}\right),
$$

where the loan market share of bank $i,\left(s_{i}\right)=(\text { loan })_{i} /$ total loan, and parameter $\beta$ is the RPD measure of competition. Parameter $\beta$ is expected to be negative because of the inverse relationship between the market shares of loans of banks and the marginal costs of banks. When competition is stronger, its effect will be too; marginal costs will also be higher, in absolute terms, since marginal costs are unobservable. We calculate marginal costs using the Translog Cost Function (TCF) with linear homogeneity in the input prices and cost exhaustion restrictions using individual bank observations. In this type of function, we assume that the technology of a bank can be described by one multiproduct production function. Under proper conditions, a dual cost function can be derived from such a production function, using augmented output levels and factor prices. A TCF is a second-order Taylor expansion around the mean of a generic dual cost function with all variables appearing as logarithms. It is a flexible functional form that has proven to be an effective tool in explaining multiproduct bank services. The TCF has the following form: 
$\ln \left(c_{i t}\right)=\alpha_{0}+\sum \alpha_{d i}+\sum t \delta_{t} d_{t}+\sum \sum \beta_{j} \ln \left(x_{i j t}\right) d_{i}+\sum \sum \sum \gamma_{j k} \ln \left(x_{i j t}\right) \ln \left(x_{i k t}\right) d_{i}+v_{i t}$

where the dependent variable $c_{i t}$ reflects the production costs of bank $i(I=1, . ., N)$ in year $t(t=1, . ., T)$ employing the $d_{i}$ dummy for the type category of the bank, that is, public, private, or foreign. The $d t$ dummy is a variable, which is 1 in year $t$, and zero otherwise. The coefficient $\gamma_{j k}$ indicates general substitution parameters between inputs and outputs. The explanatory variables $x_{i k t}$ represent three groups of variables $(k=1, \ldots, K)$. The first group consists of $(K 1)$ bank output components, such as loans, securities, and other services (proxied by other income). The second group consists of (K2) input prices, such as wage rates, deposit rates (as price of funding), and the price of other expenses (proxied as the ratio of other expenses to fixed assets). The third group consists of ( $K-K 1-K 2)$ control variables (also called 'netputs') (e.g., the capital equity ratio). In line with Berger and Mester (1997), the equity ratio corrects for differences in loan portfolio risk across banks. The coefficients $\alpha$ and $\beta_{j}$ vary with the type of bank. The parameters $\delta_{t}$ are the coefficients of the time dummies and $v_{i t}$ is the error term.

The marginal costs of output category $j=l$ (of loans) for bank $i$ of category $h$ (say) in year $t, m c_{i l t}$, are defined as:

$$
m c_{i l t}=\frac{\partial c_{i t}}{\partial x_{i l t}}=\left(c_{i t} / x_{i l t}\right) \frac{\partial \ln \left(c_{i t}\right)}{\partial \ln \left(x_{i l t}\right)}
$$

The term $\underline{\partial} \ln \left(c_{i t}\right) / \partial \ln \left(x_{i l t}\right)$ is the first derivative of equation (8) of costs to loans. This leads to the following equation of the marginal costs for the output category loans $(l)$ for bank $i$ in category $h$ during year $t$ :

$$
m c_{i l t}=\left(c_{i t} / x_{i l t}\right)\left(\beta_{l}+2 \gamma_{l} \ln \left(x_{i l t}\right)+\sum \gamma_{l k} \ln \left(x_{i k t}\right) d_{i}\right.
$$

Given the estimated marginal costs from the previous section, we are now able to estimate the RPD. We use for each bank category the marginal costs of individual banks and their market shares and estimate the following:

$$
\ln \left(s_{i t}\right)=\alpha+\sum \beta_{t} \ln \left(m c_{i t}\right)+\sum \gamma_{t} d_{t}+u_{i t}
$$

where $s$ is market share, $m c$ is marginal costs, $i$ is bank $i, t$ is year $t, d_{t}$ are time dummies, and $u_{i t}$ is the error term. This provides us with the coefficient $\beta$, the RPD. Under this static model, it is assumed that markets are always in their long-run equilibrium at each time period for which the data are observed, yielding statistics that are biased towards zero.

\section{Empirical evidence}

Reforms were instituted to induce greater efficiency in the Indian banking system. Has this purpose been achieved? There are two ways in which this question can be addressed. One is to examine accounting measures of efficiency, while another is to evaluate economic measures of efficiency. One strand of the literature on efficiency in Indian banking reports whether or not the public sector banks, which were inefficient at the commencement of reforms, have 
improved their performance; if this has happened, it augurs well for higher efficiency in the system as a whole. We begin our examination by looking at trends in accounting measures of efficiency.

\subsection{Competition}

One measure of competition in the banking sector is the share of the top five banks in assets, deposits, and profits. It can be seen in Table 1 that on all three indicators, the share of the top five banks has declined, which points to increased competition in the marketplace.

Table 1: Share of top five banks

\begin{tabular}{|c|c|c|c|c|}
\hline & Period & Assets & Deposits & Profits \\
\hline 1991-1992 & & 51.70 & 49.00 & 54.50 \\
\hline 1998-1999 & & 44.70 & 44.40 & 49.10 \\
\hline $2001-2002$ & & 43.50 & 43.30 & 41.40 \\
\hline $2007-2008$ & & 38.40 & 37.30 & 37.20 \\
\hline $2010-2011$ & & 40.79 & 36.44 & 36.41 \\
\hline
\end{tabular}

\subsection{Interest Spread}

One measure of interest spread is the ratio of net interest margin (NIM) to total assets. One would expect the spread to decline subsequent to deregulation. Deregulation measures are designed to squeeze the margins of producers and leads to an increase in volume. India's banking sector has been relatively impervious to this trend. Table 2 shows the trend in NIM in the period since deregulation. The NIM was surprisingly steady from the start of deregulation until 20062007. For three years thereafter, there was hint of a decline in NIM. In 2010-2011, however, the NIM rose again and was slightly above the level at the start of deregulation. This has, of course, been advantageous for banks, although it is counterintuitive to the rationale for deregulation.

Table 2: Net Interest Income (Spread) to Total Assets (Average)

\begin{tabular}{llllll}
\hline Period & Public Sector Banks & Old Private Sector Banks & New Private Sector Banks & Foreign Banks & Scheduled Commercial Banks \\
\hline $1992-1995$ & 2.72 & 3.24 & 1.17 & 3.98 & 2.84 \\
$1999-2000$ & 2.70 & 2.33 & 1.95 & 3.92 & 2.73 \\
$2000-2001$ & 2.86 & 2.51 & 2.14 & 3.63 & 2.85 \\
$2003-2004$ & 2.94 & 2.60 & 1.98 & 3.46 & 2.86 \\
$2004-2005$ & 2.92 & 2.70 & 2.17 & 3.33 & 2.83 \\
$2007-2008$ & 2.15 & 2.43 & 2.40 & 3.79 & 2.35 \\
$2008-2009$ & 2.10 & 2.60 & 2.80 & 3.90 & 2.40 \\
$2009-2010$ & 2.29 & 2.56 & 3.00 & 3.96 & 2.17 \\
$2010-2011$ & 2.78 & 2.95 & 3.16 & 3.86 & 2.92 \\
\hline
\end{tabular}

Efficiency, as measured by net profit to total assets, has shown an unambiguous improvement over the years and has reached $1 \%$ in recent years. (Internationally, a $1 \%$ return on assets is considered a benchmark for good performance.) It is striking that, in the years following the subprime crisis, the return on assets has remained over $1 \%$ in the Indian 
banking sector. This is a measure of how insulated the Indian banking sector is; it is also reflective of the steady improvement in fundamentals in the sector.

Table 3: Net Profit/Total Assets (\%)

\begin{tabular}{llllll}
\hline Period & Public Sector Bank & Old Private Sector Bank & New Private Sector Bank & Foreign Banks & Scheduled Commercial Bank \\
\hline $1996-1997$ & 0.57 & 0.91 & 1.73 & 1.19 & 0.67 \\
$1997-1998$ & 0.77 & 0.80 & 1.55 & 0.96 & 0.82 \\
$1998-1999$ & 0.42 & 0.48 & 1.03 & 0.69 & 0.47 \\
$1999-2000$ & 0.57 & 0.81 & 0.97 & 1.17 & 0.66 \\
$2000-2001$ & 0.42 & 0.59 & 0.81 & 0.93 & 0.49 \\
$2002-2003$ & 0.96 & 1.17 & 0.90 & 1.56 & 1.01 \\
$2004-2005$ & 0.87 & 0.33 & 1.05 & 1.29 & 0.89 \\
$2006-2007$ & 0.83 & 0.70 & 0.91 & 1.57 & 0.90 \\
$2008-2009$ & 0.90 & 1.00 & 1.10 & 1.70 & 1.00 \\
$2009-2010$ & 0.97 & 0.95 & 1.38 & 1.26 & 1.05 \\
$2010-2011$ & 0.96 & 1.12 & & 1.74 & 1.10 \\
\hline
\end{tabular}

\subsection{Operating costs}

The ratio of operating costs to total assets has declined dramatically in the post-reform era, driven largely by the decline in the ratio for the public sector banks. The most important reason is that the workforce has remained fairly constant at these banks through the initial reform years, largely due to the rising volume of work. It is only in the past three years or so that the workforce has begun to increase. Another reason is branch rationalization. The hard work of establishing branches was accomplished in the nationalization era, so public sector banks found that they did not have to invest in branches and could, in fact, close a few. Thus, banking system efficiency in the post-reform era can be said to have improved, using a set of accounting measures.

Table 4: Intermediation Costs to Total Assets Ratio (percent)

\begin{tabular}{llllll}
\hline Period & Public Sector Bank & Old Private Sector Bank & New Private Sector Bank & Foreign Banks & Scheduled Commercial Bank \\
\hline $1996-1997$ & 2.88 & 2.52 & 1.94 & 3.00 & 2.85 \\
$1997-1998$ & 2.66 & 2.31 & 1.76 & 2.97 & 2.63 \\
$1998-1999$ & 2.66 & 2.26 & 1.74 & 3.59 & 2.67 \\
$2004-2005$ & 2.09 & 1.96 & 2.06 & 2.88 & 2.13 \\
$2006-2007$ & 1.77 & 1.85 & 2.11 & 2.78 & 1.91 \\
$2007-2008$ & 1.54 & 1.66 & 2.28 & 2.84 & 1.78 \\
$2008-2009$ & 1.50 & 1.70 & 2.20 & 2.80 & 1.70 \\
$2009-2010$ & 1.61 & 1.88 & 2.16 & 2.52 & 1.78 \\
$2010-2011$ & 1.70 & 1.94 & 2.23 & 2.71 & 1.86 \\
\hline
\end{tabular}




\subsection{Non-parametric RPD estimation}

The non-parametric RPD is defined as follows:

$$
R P D_{i t}=\frac{\pi_{t}(i)-\pi_{t}\left(i_{L}\right)}{\pi_{t}\left(i_{U}\right)-\pi_{t}\left(i_{L}\right)},
$$

where $\pi_{t}$ is profit at time $t, i$ is the bank whose RPD is measured, and $\left[i_{L}, i_{U}\right]$ is the set of banks belonging to a given industry and ranked by cost efficiency, from the less efficient banks, $i_{L}$, to the more efficient banks, $i_{U}$. One convenient way, proposed by Boone (2008), is to graph the RPDs using a bank's normalized efficiency and normalized profits. An increase in competition leads to lower bank-specific RPDs. To measure the change in competition, calculate and compare the area under a curve. Since we have normalized values, the area is bounded between zero and one, with zero implying perfect competition and one the complete absence of competition. In this case, the more competitive a sector, the more the curved line would be pulled to the bottom right. The levels of competition within a sector can be computed as the area below the RPD curve. The smaller the area below the curve, the higher the level of competition within a sector. The non-parametric values of RPD were calculated from the dataset and are compared with two other commonly-used measures of competition in Table 5.

Table 5: Different Measures of Competition

\begin{tabular}{llll}
\hline Year & RPD (Non-parametric) & H-stat & PCM \\
\hline 1996 & 0.357 & 0.666 & 0.514 \\
1997 & 0.315 & 0.734 & 0.553 \\
1998 & 0.347 & 0.646 & 0.504 \\
1999 & 0.399 & 0.627 & 0.463 \\
2000 & 0.479 & 0.633 & 0.427 \\
2001 & 0.392 & 0.615 & 0.427 \\
2002 & 0.185 & 0.440 & 0.344 \\
2003 & 0.434 & 0.466 & 0.423 \\
2004 & 0.513 & 0.646 & 0.454 \\
2005 & 0.468 & 0.656 & 0.467 \\
2006 & 0.429 & 0.458 & 0.462 \\
2007 & 0.521 & 0.616 & 0.448 \\
2008 & 0.620 & 0.584 & 0.397 \\
2009 & 0.668 & 0.492 & 0.332 \\
2010 & 0.691 & 0.503 & 0.381 \\
2011 & 0.632 & 0.514 & 0.402 \\
\hline
\end{tabular}


The results for the traditional Lerner Index (PCM) in Table 5 indicate a general decrease in bank competition up to around 2002; an increase in bank competition begins in 2003. Moreover, the traditional Lerner Index indicates a nonconsistent trend of an increase in competition for most years. Furthermore, the H-statistics are significantly different from zero and one for all years, rejecting the null hypothesis that the loan markets in India are in a state of either perfect competition or monopoly. The H-statistic measure performed better than the PCM measure but is not consistent when compared with the RPD measure.

\subsection{Parametric ARPD estimation}

It is evident from Table 5 that the RPD value over the sample period is highly volatile. This volatility may be assumed to be due to the non-parametric measurement technique, which employs normalized efficiency and normalized profitability. The RPD measure gives a better idea of the state and process of competitiveness in the loan market as compared to conventional H-statistics and the PCM measure. We used the ARPD measure suggested by Leuvensteijn (2008) to measure competition. We estimated marginal costs using Translog Cost Function. As shown in Table 6, competition measured using the ARPD measure is statistically significant in a consistent manner for all the banks. As it is known from the theory proposed by Boone (2008), in an absolute sense, higher coefficients indicate higher competition. We conclude that competitiveness in both private sector banks and public sector banks has decreased as compared to foreign banks during the sample period. Competition in the banking sector increased after 2002, except for a marginal decrease during 2006-2007. All the coefficients are between 0 and 1, which indicates the monopolistic nature of competitiveness in the loan market in India. The ARPD measure quantifies the impact of marginal costs on performance, measured in terms of market share. Here the original RPD is improved by calculating marginal costs instead of approximating marginal costs using average variable costs. After the recent financial crisis, foreign banks have been adversely affected in terms of competition as compared to both the public sector and private sector banks. Competition levels for the foreign banks fluctuate due to their risk-taking behavior and global risk exposure. Overall, according to the ARPD measure, competitive conditions in the loan markets have increased over the study period. The loan markets in India are found to be monopolistic in nature.

Table 6: The ARPD Measure of Competition

\begin{tabular}{lllll}
\hline ARPD Measure & ALL & PSB & PVT & FRN \\
\hline 1996 & $-0.315(0.086)^{* *}$ & $-0.304(0.084)^{* *}$ & $-0.228(0.057)^{* *}$ & $-0.338(0.308)$ \\
1997 & $-0.340(0.087)^{* *}$ & $-0.329(0.085)^{* *}$ & $-0.242(0.058)^{* *}$ & $-0.357(0.300)$ \\
1998 & $-0.356(0.085)^{* *}$ & $-0.345(0.086)^{* *}$ & $-0.227(0.056)^{* *}$ & $-0.672(0.341)^{*}$ \\
1999 & $-0.307(0.086)^{* *}$ & $-0.296(0.081)^{* *}$ & $-0.189(0.057)^{* *}$ & $-0.547(0.359)$ \\
2000 & $-0.384(0.091)^{* *}$ & $-0.374(0.091)^{* *}$ & $-0.235(0.061)^{* *}$ & $-0.414(0.348)^{* *}$ \\
2001 & $-0.359(0.088)^{* *}$ & $-0.346(0.087)^{* *}$ & $-0.223(0.058)^{* *}$ & $-0.420(0.395)^{*}$ \\
2002 & $-0.453(0.091)^{* *}$ & $-0.442(0.091)^{* *}$ & $-0.299(0.059)^{* *}$ & $-0.392(0.432)^{* *}$ \\
2003 & $-0.404(0.086)^{* *}$ & $-0.395(0.086)^{* *}$ & $-0.363(0.057)^{* *}$ & $-0.470(0.343)^{* *}$ \\
2004 & $-0.384(0.080)^{* *}$ & $-0.376(0.079)^{* *}$ & $-0.357(0.054)^{* *}$ & $-0.504(0.261)^{* *}$ \\
2005 & $-0.390(0.067)^{* *}$ & $-0.432(0.067)^{* *}$ & $-0.409(0.046)^{* *}$ & $-0.320(0.201)^{* *}$ \\
2006 & $-0.341(0.061)^{* *}$ & $-0.433(0.060)^{* *}$ & $-0.431(0.041)^{* *}$ & $-0.499(0.187)^{* *}$ \\
2007 & $-0.360(0.051)^{* *}$ & $-0.543(0.051)^{* *}$ & $-0.423(0.034)^{* *}$ & $-0.475(0.174)^{* *}$ \\
\hline
\end{tabular}




\begin{tabular}{lllll}
\hline 2008 & $-0.388(0.061)^{* *}$ & $-0.513(0.051)^{* *}$ & $-0.421(0.042)^{* *}$ & $-0.563(0.180)^{* *}$ \\
2009 & $-0.452(0.050)^{* *}$ & $-0.603(0.051)^{* *}$ & $-0.531(0.033)^{* *}$ & $-0.644(0.193)^{* *}$ \\
2010 & $-0.448(0.059)^{* *}$ & $-0.572(0.062)^{* *}$ & $-0.543(0.032)^{* *}$ & $-0.663(0.178)^{* *}$ \\
2011 & $-0.493(0.063)^{* *}$ & $-0.656(0.059)^{* *}$ & $-0.625(0.034)^{* *}$ & $-0.694(0.184)^{* *}$ \\
\hline
\end{tabular}

On average, competition in the loan markets has increased. It is evident from Table 6 that both public sector and private sector banks have higher ARPD levels, although private sector levels have increased at a more rapid pace. The foreign sector banks were comparatively less competitive up to 1999, but increased continuously until 2005. The ARPD of the foreign banks decreased during the onset of the financial crisis, but increased gradually thereafter.

\section{Conclusion}

In this study, we measured bank competition in the Indian loan markets using a new competitiveness index, the Augmented Relative Profit Difference (ARPD) index. This index can be used to quantify the impact of marginal costs on performance, measured in terms of market share. The original Boone RPD is enhanced by calculating marginal costs instead of approximating marginal costs using average variable costs. The conventional measures of competition, such as the Lerner Index and the Panzar and Rosse H-statistic, did not perform as well as those estimated using the ARPD approach. We argue that traditional measures of competition fail to adequately measure competition in the Indian banking sector.

Using balance sheet information for a large sample of banks operating in India during 1996-2011, we show that competition actually increased in the past decade when using the ARPD measure introduced by Boone et al. (2007) and Boone (2008) as a theoretically robust competitiveness index to measure competition in loan markets. This study yields two major insights. First, the theoretical foundation of the ARPD is very robust as compared to other conventional measures. This makes the ARPD a much better measure to evaluate competition in a single sector of an industry, say Indian loan markets, than conventional approaches. This is a general insight that can be useful for investigations of competitive conditions in banking markets in a particular sector. Second, applying this unbiased competition indicator to India loan markets shows that recent financial reform measures contributed to significant improvements in competition. Again, we find contradictory results for the conventional measures.

We found that public sector banks and private sector banks are comparatively more competitive than foreign banks. All in all, according to the ARPD measure, competitive conditions in the loan markets in India over time increased and the ARPD values lie between zero and one. This finding indicates that the Indian loan markets are monopolistic in nature. 


\section{References}

Ansari, J. and Goyal, A., (2011). Competition in the Banking Sector and Monetary Transmission Mechanism: An Empirical Analysis of Interest Rate Pass-through in India. Mimeo.

Aghion, P., N. Bloom, R. Blundell, R. Griffith, P. Howitt (2005). Competition and Innovation: An Inverted-U Relationship. Quarterly Journal of Economics, 120 (2): 701-728.

Amir, R. (2003). Market Structure, Scale Economies and Industry Performance. CORE Discussion Paper Series 2003/65.

Barth, James R., Gerard Caprio Jr., and Ross Levine (2004). Bank Regulation and Supervision: What Works Best? Journal of Financial Intermediation, Journal of Financial Intermediation, 13(2), 205-248.

Baumol, W.J., J.C. Panzar, and R.D. Willing (1982). Contestable Markets and the Theory of Industry Structure, San Diego: Harcourt Brace Jovanovich.

Beck, T., A. Demirguc-Kunt, and R. Levine (2003). Bank Concentration and Crises. Presented at the Conference on Bank Concentration and Competition at the World Bank.

Berger, A. (1995). The Profit-Structure Relationship in Banking-Tests of Market Power and Efficient-Structure Hypothesis. Journal of Money, Credit, and Banking, 27: 404-31.

Berger, A. and T. Hannan (1989). The Price-Concentration Relationship in Banking, Review of Economics and Statistics, 71: 291-99.

Besanko, D. and A.V. Thakor (1992). Banking Deregulation: Allocational Consequences of Relaxing Entry Barriers. Journal of Banking and Finance, 16: 909-32.

Bhanu Murthy and Deb (2008). Operationalizing and Measuring Competition: Determinants of Competition in Private Banking Industry in India. MPRA Paper number 7463.

Bikker, J. and K. Haaf (2002). Competition, Concentration and Their Relationship: An Empirical Analysis of the Banking Industry. Journal of Money, Credit and Banking, 35: 2191-214.

Bikker, J.A., M. von Leuvensteijn (2008). Competition and efficiency in the Dutch life insurance industry. Applied Economics, 40: 2063-2084.

Boone, J. (2004). A new way to measure competition. CEPR Discussion Paper No. 4330.

Boone, J., J. van Ours, H. van der Wiel (2007). How (not) to measure competition, CPB Paper No 91.

Boone, J. (2008), “A new way to measure competition”, The Economic Journal, 188: 1245-1261.

Bulow, J. and Klemperer, P. (1999). Prices and the winner's curse. RAND Journal of Economics, vol. 33 (1), 1-21.

Bresnahan, T. (1982). The Oligopoloy Solution Concept is Identified. Economics Letters, 10: 87-92.

Bresnahan, Timothy F. (1989). Studies of Industries with Market Power. In Handbook of Industrial Organization, Vol. II, edited by Richard Schmalensee and Robert D. Willig, pp. 1011-1057.

Cetorelli, N. (2004). Real Effects of Bank Competition. Federal Reserve Bank of Chicago Working Paper No. 3.

De Bandt, Olivier, and E. Philip Davis (2000). Competition, Contestability and Market Structure in European Banking Sectors on the Eve of EMU. Journal of Banking and Finance, 24, 1045-1066.

Gruben, William C., and Robert P. McComb (2003). Privatization, Competition, and Super-competition in the Mexican Commercial Banking System. Journal of Banking and Finance, 27, 229-249.

Hannan, T. (1991). Bank Commercial Loan Markets and the Role of Market Structure: Evidence from Surveys of Commercial Lending. Journal of Banking and Finance, 15: 133-49. 
Leuvensteijn, V, M., J.A. Bikker, A. van Rixtel, and C. Kok Sorensen (2007). A new approach to measure competition in the loan markets of the euro area. ECB Working Paper Series No. 768.

Nathan, A. and E. Neave. (1989). Competition and Contestability in Canada's Financial System: Empirical Results. Canadian Journal of Economics, xxii(3): 576-94.

Nickell, S. (1996). Competition and Corporate Performance. Journal of Political Economy, 140 (4): 724-746.

Panzar, John C., and James N. Rosse (1982). Structure, Conduct and Comparative Statistics., Bell Laboratories Economics Discussion Paper.

Panzar, J.C. and J.N. Rosse (1987). Testing for monopoly equilibrium, The Journal of Industrial Economics, 35(4): $443-56$.

Petersen, M. and R.G. Rajan (1995). The Effect of Credit Market Competition on Lending Relationships. The Quarterly Journal of Economics, 110: 407-43.

Prasad, A. and Ghosh, S. (2005). Competition in Indian Banking. IMF Working Papers number 05/141.

Reddy, Y.V. (2002). Public Sector Banks and the Governance Challenge: Indian Experience. RBI Bulletin, May, 337356.

Shaffer, Sherrill (1982). A Non-structural Test for Competition in Financial Markets. In Bank Structure and Competition. Conference Proceedings, Federal Reserve Bank of Chicago, pp. 225-243.

Shaffer, Sherrill (1983). Non-structural Measures of Competition: Toward a Synthesis of Alternatives, Economic Letters, 12, 349-353.

Shaffer, Sherrill (1989), "Competition in the U.S. Banking Industry", Economics Letters 29, 321-323.

Shaffer, S. (1993). A Test of Competition in Canadian Banking. Journal of Money, Credit and Banking, 25(1): 49-61.

Shaffer, Sherrill (2001). Banking Conduct before the European Single Banking License: A Cross-Country Comparison. North American Journal of Economics and Finance, 12, 79-104.

Shaffer, S. (2002). Competitive Bank Pricing and Adverse Selection, With Implications for Testing the SCP Hypothesis. The Quarterly Review of Economics and Finance, 42(3): 633-47.

Wolfram, C. (1999). Measuring duopoly power in the British electricity spot market, American Economic Review, vol. 89 (4), 805-26. 